\section{SOI: 1.1/TAS DOI: $10.15863 /$ TAS International Scientific Journal Theoretical \& Applied Science}

p-ISSN: 2308-4944 (print) ｅ-ISSN: 2409-0085 (online)

Year: 2017 Issue: $07 \quad$ Volume: 51

Published: $30.07 .2017 \quad \underline{\text { http://T-Science.org }}$

SECTION 1. Theoretical research in mathematics
Vladimir Aleksandrovich Mushrub Ph.D., associate professor at the Academic Department of Mathematical Methods in Economics of the Russian Plekhanov University of Economics, Moscow mushrub@yandex.ru

Irina Vladimirovna Sukhorukova Doctor of Economics, Professor of the Mathematical Department of the Russian Plekhanov University of Economics, Moscow, suhorukovaira@yandex.ru

Ekaterina Pavlovna Mochalina Ph.D., assistant professor of the Mathematics Department of the Russian Plekhanov University of Economics,

Moscow mochalina77@yandex.ru

Galina Vladimirovna Ivankova Senior lecturer of the Mathematics Department of the Russian Plekhanov University of Economics, Moscow g_ivankova@mail.ru

\title{
ON F-PRIME RINGS AND THEIR F-RINGS OF QUOTIENTS
}

\begin{abstract}
All rings are associative in what follows. We will also assume that all rings are unital and all ring homomorphisms preserve the identity. Throughout the paper, B stands for a unitary associative ring and $f$ is an automorphism of $B$. The main purpose of the work is to describe the left f-ring of quotients $Q_{f}(B)$ of $B$. Our methods is not connected with right flat epimorphic hull, but we use a fruitful construction based on a direct limit to build the $f$-ring of quotients. The principal results to be given are Theorems 1 and 2 below. Theorem 1 establishes that $Q_{f}(B)$ is embeddable in the complete left ring of quotients $Q_{\max }(B)$ and the ring $B$ is a subring of $Q_{f}(B)$. Theorem 2 asserts that the centres of the left and right f-ring of quotients rings coincides. The authors have intention to continue this study in their subsequent articles. Therefore, at the end of the paper, we formulate a hypothesis, for the proof of which we need the results of this work.

Key words: associative rings; f-rings of quotients; f-prime rings.

Language: English

Citation: Mushrub VA, Sukhorukova IV, Mochalina EP, Ivankova GV (2017) ON F-PRIME RINGS AND THEIR F-RINGS OF QUOTIENTS. ISJ Theoretical \& Applied Science, 07 (51): 107-110.

Soi: http://s-o-i.org/1.1/TAS-07-51-18 Doi: crossef https://dx.doi.org/10.15863/TAS.2017.07.51.18
\end{abstract}

\section{Introduction}

All rings in this paper are associative with multiplicative identity and all ring homomorphisms are assumed preserve the identity.

Definition 1. Let $R$ be a ring and $F$ be an injective ring endomorphism of $R$.

Let $N$ be a subset of $R$. We say that $N$ is an $F$ subset if $F^{-1}(N)=N$. Similarly, we shall say that an ideal $N$ of $R$ is an $F$-ideal if $N$ is an $F$-subset (see [3], [4], [6], [14]). A ring $R$ is said to be $F$-prime if the product of any two nonzero $F$-ideals of $R$ is nonzero. In other words, ring $R$ is $F$-prime if the product of any two $F$-ideals $P$ and $N$ is equal to the zero ideal if and only if either $P=0$ or $N=0$.

Lemma 1. Let $A$ be a ring and $f$ be an automorphism of $A$. Then the following conditions (1)-(5) are equivalent:
(1) $A$ is $f$-prime;

(2) for any two left $f$-ideals $I$ and $J$ of $A$, the equality $I J=0$ implies that either $I=0$ or $J=0$;

(3) $a \sum_{i \in \mathbb{Z}} A f^{i}(b) \neq 0$ for every $a, b \in A$;

(4) $r_{A}(I)=0$ for every nonzero $f$-ideals $I$ of $A$;

(5) $\ell_{A}(I)=0$ for every nonzero $f$-ideals $I$ of $A$.

\section{Materials and Methods}

Throughout the sequel, $B$ will denote a ring, $f$ will stand for an automorphism of $B$ and we will always assume that the $\operatorname{ring} B$ is $f$-prime. We denote by $\Phi(B)$ the set of all nonzero $f$-ideals of $B$.

Despite the fact that rings of rings for along time are classical objects of study, the rings of quotients have been actively studied recently (see, 


\begin{tabular}{|c|c|c|c|c|c|c|}
\hline Impact Factor: & $\begin{array}{l}\text { ISRA (India) } \\
\text { ISI (Dubai, UAE } \\
\text { GIF (Australia) } \\
\text { JIF }\end{array}$ & $\begin{array}{l}=1.344 \\
=0.829 \\
=0.564 \\
=1.500\end{array}$ & $\begin{array}{l}\text { SIS (USA) } \\
\text { PИНЦ (Russia) } \\
\text { ESJI (KZ) } \\
\text { SJIF (Morocco) }\end{array}$ & $\begin{array}{l}=0.912 \\
=0.234 \\
=\mathbf{3 . 8 6 0} \\
=\mathbf{2 . 0 3 1}\end{array}$ & $\begin{array}{l}\text { ICV (Poland) } \\
\text { PIF (India) } \\
\text { IBI (India) }\end{array}$ & $\begin{array}{l}=6.630 \\
=1.940 \\
=4.260\end{array}$ \\
\hline
\end{tabular}

for example, [1], [2]). Now we define the left $f$-ring of quotients of the ring $B$.

We denote by $M$ the set of all the pair of the form $(I, \alpha)$ where $I \in \Phi(B)$ and $\alpha: I \longrightarrow B$ is a homomorphism of left $B$-modules. Since $B$ is $f$-prime, we have $0 \neq I J \subseteq I \cap J$ for all $I, J \in \Phi(B)$. Определим отношение эквивалентности $\theta$ на множестве $M$ так: положим $(I, \alpha) \sim(J, \beta)$, если существует ненулевой $f$-идеал $K \subset I \cap J$ такой, что $\alpha(x)=\beta(x)$ для всех. Let us define the equivalence relation $\theta$ on the set $M$ as follows: we put $(I, \alpha) \sim(J$, $\beta$ ) if there exists a nonzero $f$-ideal $K \subseteq I \cap J$ such that $\alpha(x)=\beta(x)$ for all $x \in K$. We denote by $[I, \alpha]$ the equivalence class containing the pair $(I, \alpha)$. Let $Q_{f}(B)=M / \theta$ (the set of all equivalence classes)

The set $Q_{f}(B)$ turn into a ring if we define on it the following operations:

$$
\begin{aligned}
{[I, \alpha]+[J, \beta] } & =[I \cap J, \alpha+\beta], \\
-[I, \alpha] & =[I,-\alpha], \\
{[I, \alpha] \cdot[J, \beta] } & =[I \cap J, \alpha \circ \beta] .
\end{aligned}
$$

Definition 2. The ring $Q_{f}(B)$ described above is called the left (Martindale) $f$-ring of quotients of $B$.

Remark. One can formalize the construction of $Q_{f}(B)$ as the direct limit

$$
Q_{f}(B)=\lim _{\rightarrow}\left(\operatorname{Hom}_{B}\left({ }_{B} I,{ }_{B} B\right): I \in \Phi(B)\right) .
$$

If every ideal of $B$ is an $f$-ideal, then $Q_{f}(B)$ coincides with the left ring of quotients in the sense of Martindale.

We define analogously the right $f$-ring of quotients of $B$ (in the sense of Martindale) as follows:

$$
Q_{f}^{r}(B)=\underset{\rightarrow}{\lim }\left(\operatorname{Hom}_{B}\left(I_{B}, B_{B}\right): I \in \Phi(B)\right) .
$$

Lemma 2. Let $I \in \Phi(B), \lambda$ be a left ideal of $B$ and $\alpha, \beta: I \rightarrow B$ be a homomorphism of left $B$-modules. Suppose that $\alpha(x)=\beta(x)$ for all $x \in$ $I \cap J$. Then $\alpha \equiv \beta$.

Proof. Take any $b \in J$. If $a \in I$ then $a b \in I \cap J$ and $\alpha(a b)=\beta(a b)$. Hence, $a(\alpha(b)-\beta(b))=0$ for all $a \in I$. But $r_{A}(I)=0$ by Lemma 1. It follows that $\alpha(b)=\beta(b)$ for all $b \in J$. QED.

The above $f$-ring of quotients $Q_{f}(B)$ possesses some properties of the usual Martindale ring of quotients. In particular, we have the following theorem.

Theorem 1. The $f$-ring of quotients $Q_{f}(B)$ is embeddable in the maximal left ring of quotients $Q_{\max }(B)$ and the ring $B$ is a subring of the ring $Q_{f}(B)$.

Proof. If $I \in \Phi(B)$ then $r_{B}(I)=0$ by Lemma 1 and, hence, $I$ is a dense right ideal of $B$. Therefore, to each element $q=[I, \alpha] \in Q_{f}(B)$ can be match up with the element $\left.\varphi(q) \in Q_{\max }(B)\right)$ such that $x \varphi(q)=\alpha(x)$ for all elements $x \in I$.

One can easily verify that the mapping $q \mapsto$ $\varphi(q)$ is a correctly defined injective ring homomorphism. Furthermore, according to the construction $\varphi\left(Q_{f}(B)\right)=\left\{q \in Q_{f}(B)\right.$ : there exists an ideal $I \in \Phi(B)$ such that $I q \subseteq B\}$. Each element $a \in B$ defines the homomorphism of left $B$-modules

$$
\alpha_{a}: x \mapsto x a(x \in B) .
$$

Since $B \in \Phi(B)$, the equivalence class $\left[B, \alpha_{a}\right]$ belongs to $Q_{f}(B)$ ). This gives a natural embedding $B \subseteq Q_{f}(B)$. QED.

In what follows we identify the $\operatorname{rings} Q_{f}(B)$ and $\varphi\left(Q_{f}(B)\right)$.

Let $q \in Q_{f}(B)$. We denote by $J(q)$ the sum of all $f$-ideals $I$ of $B$ such that $I q \subseteq B$. Observe that $J(q)$ itself is also an $f$-ideal and $J(q) \cdot q \subseteq B$. Таким образом, $J(q)$ - наибольший идеал среди $f$-идеалов $I$ кольца $B, \quad$ обладающих свойством $I q \subseteq B$.

Thus, $J(q)$ is the largest ideal among $f$-ideals $I$ of $B$ having the property $I q \subseteq B$.

If $q \in Q_{\max }(B)$ then we set $D(q)=\{a \in$ $\left.Q_{\max }(B): a q \in B\right\}$. As is well known in the theory of rings of quotients, the automorphism $f$ can be uniquely extended to an automorphism of $Q_{\max }(B)$. We will denote this extension by the same symbol $f$. Since $f(D(q)) \cdot f(q)=f(D(q) q) \in f(B)=B$ and $f^{-1}(D(f(q))) \cdot q=f^{-1}(D(f(q)) \cdot f(q)) \in$ $f^{-1}(B)=B$, we get $f(D(q))=D(f(q))$.

Let us consider any element $q \in Q_{f}(B)$ and note the following: if $x \in J(q)$ then both $f(x)$ and $f^{-1}(x)$ lie in $J(q)$, and therefore we have that $x f(q)=$ $f\left(f^{-1}(x) q\right) \in B$ and $x f^{-1}(q)=f^{-1}(f(x) q) \in B$. It follows that $J(q) f(q) \subseteq B$ and $J(q) f^{-1}(q) \subseteq B$. Consequently, $\quad f\left(Q_{f}(B)\right) \subseteq Q_{f}(B) \quad$ and $f^{-1}\left(Q_{f}(B)\right) \subseteq Q_{f}(B)$. Thus, $f$ can be regarded as an automorphism of $Q_{f}(B)$.

Proposition 1. The $f$-ring of quotients $Q_{f}(B)$ introduced above has the following properties.

(1). For any elements $q_{1}, q_{2}, \ldots, q_{n} \in Q_{f}(B)$, there exists an ideal $I \in \Phi(B)$ such that $I q_{i} \subseteq B$ for all $i=1,2, \ldots, n$.

(2). If $I q=0$ for some ideal $I \in \Phi(B)$ and some element $q \in Q_{f}(B)$, then $q=0$.

(3). If $q I=0$ for some ideal $I \in \Phi(B)$ and some element $q \in Q_{f}(B)$, then $q=0$.

(4). If $I \in \Phi(B)$ and $\gamma: I \rightarrow B$ is a homomorphism of left $B$-modules, then there is an element $q \in Q_{f}(B)$ such that $\gamma(x)=x q$ for all elements $x \in I$.

(5). $Q_{f}(B)$ is an $f$-prime ring. 


\begin{tabular}{|c|c|c|c|c|c|c|}
\hline Impact Factor: & $\begin{array}{l}\text { ISRA (India) } \\
\text { ISI (Dubai, UAF } \\
\text { GIF (Australia) } \\
\text { JIF }\end{array}$ & $\begin{array}{l}=1.344 \\
=0.829 \\
=0.564 \\
=1.500\end{array}$ & $\begin{array}{l}\text { SIS (USA) } \\
\text { PИНЦ (Russia) } \\
\text { ESJI (KZ) } \\
\text { SJIF (Morocco) }\end{array}$ & $\begin{array}{l}=0.912 \\
=0.234 \\
=\mathbf{3 . 8 6 0} \\
=\mathbf{2 . 0 3 1}\end{array}$ & $\begin{array}{l}\text { ICV (Poland) } \\
\text { PIF (India) } \\
\text { IBI (India) }\end{array}$ & $\begin{array}{l}=6.630 \\
=1.940 \\
=4.260\end{array}$ \\
\hline
\end{tabular}

Proof. (1). As the required ideal, we can take the ideal

$$
I=J\left(q_{1}\right) \cap J\left(q_{2}\right) \cap \ldots \cap J\left(q_{n}\right) .
$$

It works, because $B$ is an $f$-prime ring and

$0 \neq J\left(q_{1}\right) J\left(q_{2}\right) \cdots J\left(q_{n}\right) \subseteq J\left(q_{1}\right) \cap J\left(q_{2}\right) \cap \ldots$ $\cap J\left(q_{n}\right)$.

(2). This follows from Lemma 2 and the definition of the $f$-ring of quotients.

(3). Observe that $P=\sum_{i \in \mathbb{Z}} J(q) f^{i}(q)$ is the left $f$-ideal of $B$ and $P I=\sum_{i \in \mathbb{Z}} J(q) f^{i}(q I)=0$. Since is an $f$-prime ring, then $P=0$. Therefore, $J(q) q=0$ and $q=0$.

(4). This assertion follows immediately from Definition 2.

(5). Let $a$ and $b$ be two non-zero elements of

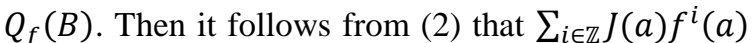
and $\sum_{i \in \mathbb{Z}} J(b) f^{i}(b)$ are non-zero left $f$-ideals. Since $B$ is an $f$-prime ring, we get that $\sum_{i \in \mathbb{Z}} J(a) f^{i}(a)$. $\sum_{i \in \mathbb{Z} J} J(b) f^{i}(b) \neq 0$. Hence, it follows that $a$. $\sum_{i \in \mathbb{Z} J} J(b) f^{i}(b) \neq 0$ and, by Lemma $1, Q_{f}(B)$ is an $f$-prime ring. QED.

We denote by $C(B)$ and $C^{r}(B)$ the center of the left maximal and right maximal rings of quotients of $\mathrm{B}$, correspondingly. One more piece of notation: $C_{f}(B)=\{c \in C(B): f(b)=b\} \quad$ and $\quad C_{f}^{r}(B)=$ $\left\{c \in C^{r}(B): f(b)=b\right\}$.

Theorem 2.

(1). If $q \in \mathrm{C}_{f}(B)$, then the set $D(q)=$ $\{b \in B \mid b q \in B\}$ is an f-ideal.

(2). $\mathrm{C}_{f}(B)$ is the center of $Q_{f}(B)$.

(3). If $q=[I, \alpha] \in Q_{f}(B)$, then $q \in \mathrm{C}_{f}(B)$ if and only if $\alpha$ is a homomorphism of bimodules over the ring $B$.

(4). The rings $C_{f}(B)$ and $C_{f}^{r}(B)$ are isomorphic.

Proof. (1). Let $a \in B$. Then $q a \in B$ if and only if $f(q a)=f(a) q \in B$. Therefore, $D(q) \in \Phi(B)$.

Assertion (2) follows from assertion (1) since $\mathrm{C}_{f}(B)$ is the centralizer of the set $B$ in $Q_{\max }(B)$.

(3). If $\alpha$ is a homomorphism of bimodules over the ring $B$, then, as is easily seen, $q \in \mathrm{C}(B)$ and therefore $q \in \mathrm{C}_{f}(B)$. The converse follows from assertion (1).

(4). Using assertion (3), one can prove that both rings $C_{f}(B)$ and $C_{f}^{r}(B)$ are isomorphic to the ring $\left\{c \in \lim \left(\operatorname{Hom}_{B}\left({ }_{B} I_{B},{ }_{B} B_{B}\right): I \in \Phi(B)\right) \mid f(c)=c\right\}$. $\overrightarrow{\mathrm{QED}}$.

Theorem 3. Let $B$ be an $f$-prime ring and $0 \neq q \in$ $Q_{f}(B)$. If $q f(a)=a q$ for all elements $a \in B$, then $q$ is an invertible element of the ring $Q_{f}(B)$ and $f$ is an inner automorphism of the $\operatorname{ring} Q_{f}(B)$ defined by the element $q$ :

$$
f(p)=q^{-1} p q\left(\forall p \in Q_{f}(B)\right) .
$$

Proof. For brevity, we denote by $Q$ the ring of quotients $Q_{f}(B)$. Let $p$ be an arbitrary element of the ring $\mathrm{Q}$ and let $\mathrm{k}$ be an integer. Then for each elements $a \in B$, we have a chain of equalities:

$$
\begin{gathered}
f^{k}(q) f(a)=f^{k}\left(q f^{1-k}(a)\right)=f^{k}\left(f^{-k}(a) q\right)= \\
=a f^{k}(q) .
\end{gathered}
$$

We recall that $J(p)$ denotes the largest among the $f$-ideals $I$ of $B$ with the property $I p \subseteq B$. It follows from (1) that for all elements $a \in J(p)$ the following equalities hold:

$$
\begin{gathered}
a f^{k}(q) f(p)=f^{k}(q) f(a) f(p)=f^{k}(q) f(a p) \\
=a p f^{k}(q) . \\
\text { Hence } J(p)\left(f^{k}(q) f(p)-p f^{k}(q)\right)=0 .
\end{gathered}
$$

Therefore, $f^{k}(q) f(p)-p f^{k}(q)=0$ by Proposition 1. Consequently,

$f^{k}(q) f(p)=p f^{k}(q)(\forall p \in Q \forall k \in \mathbb{Z})$

and in particular,

$$
f^{k}(q) Q=Q f^{k}(q)
$$

The ring $Q$ is $f$-prime by Proposition 1 . Therefore, it follow from Lemma 1 that $a \sum_{i \in \mathbb{Z}} Q f^{i}(b) \neq 0$ for any two non-zero elements $a, b \in Q$. Hence, $q \sum_{i \in \mathbb{Z}} f^{i}(q) Q=q \sum_{i \in \mathbb{Z}} Q f^{i}(q) \neq 0$ by (3), and therefore $q f^{k}(q) \neq 0$ for some integer $k$. We set $u=$ $q f^{k}(q)$ and note that, by virtue of (2), we obtain that

$$
\begin{gathered}
p u=p q f^{k}(q)=q f(p) f^{k}(q)=q f^{k}(q) f^{2}(p) \\
=u f^{2}(p)
\end{gathered}
$$

for all $p \in Q$. Moreover, equality (1) leads to the invariance of the element $u$ :

$u=q f^{k}(q)=f^{k}(q) f(q)=f(q) f\left(f^{k}(q)\right)=f(u)$.

So, we have proved that

1) $u Q=Q u$ (this follows from equality (4));

2) $f(u)=u$. lemma.

To complete the proof, we need the following

Lemma 3 ([9, Lemma 1.2]). If an element $u \in Q$ satisfies conditions 1) and 2), then $u$ is an invertible element in the ring $Q$.

To finish the proof, it remains to note that $q$ also turns out to be an invertible element of the ring $Q$. Indeed, $\quad q f^{k}(q) u^{-1}=u u^{-1}=1 \quad$ and $u^{-1} f^{k-1}(q) q=u^{-1} q f^{k}(q)=u^{-1} u=1$. It follows from (2) that $q f(p)=p q$ for all elements $p \in Q$. Since $q$ is invertible, $f(p)=q^{-1} p q(\forall p \in Q)$. QED.

Now we formulate an open problem:

Let $R$ be a ring an $f$-prime ring, and $A$ be the Cohn-Jordan extension of $R$ by means of $f$ (see [10], [11], [12], [14]). The one can prove that $A$ is also $f$ prime. It would be interesting to clarify the relationship between the $f$-rings of quotients of rings $R$ and $A$. 


\begin{tabular}{|c|c|c|c|c|c|c|}
\hline Impact Factor: & $\begin{array}{l}\text { ISRA (India) } \\
\text { ISI (Dubai, UAE } \\
\text { GIF (Australia) } \\
\text { JIF }\end{array}$ & $\begin{array}{l}=1.344 \\
=0.829 \\
=0.564 \\
=1.500\end{array}$ & $\begin{array}{l}\text { SIS (USA) } \\
\text { PИНЦ (Russia } \\
\text { ESJI (KZ) } \\
\text { SJIF (Morocco }\end{array}$ & $\begin{array}{r}=\mathbf{0 . 9 1 2} \\
=\mathbf{0 . 2 3 4} \\
=\mathbf{3 . 8 6 0} \\
=\mathbf{2 . 0 3 1}\end{array}$ & $\begin{array}{l}\text { ICV (Poland) } \\
\text { PIF (India) } \\
\text { IBI (India) }\end{array}$ & $\begin{array}{l}=6.630 \\
=1.940 \\
=4.260\end{array}$ \\
\hline
\end{tabular}

\section{Conclusion}

At the end of the present work, let us make the following hypothesis, which will be verified in the subsequent author's works:

Let $R$ be a ring and $\mathrm{F}$ be an injective endomorphism of $R$. Suppose that the skew polynomial ring $R[x, F]$ is semiprime. Let $(A, f)$ be the Cohn-Jordan extension of the pair $(R, f)$. This is extension described in [3], [4], and [5]. We denote by
$Q$ the maximal left ring of quotients of $A$ and denote by $\mathfrak{D}_{*}$ the orthogonal completion of the center of the ring of oblique Laurent polynomials $Q\langle x, f\rangle$ in the maximal left ring of quotients of $Q\langle x, f\rangle$. Then the extended centroid of the ring $R[x, F]$ is isomorphic to the complete left classical ring of quotients $\mathfrak{D}_{*}^{-1} \mathfrak{D}_{*}$.

\section{References:}

1. Balaba I.N, Kanunnikov A.L, Mikhalev A.V. (2015) Graduirovannyye kol'tsa chastnykh. Algebra, teoriya chisel i diskretnaya geometriya: sovremennyye problemy i prilozheniya, Materials of the XIII International Conference, Tula, - p. 12-15.

2. Balaba I.N., Kanunnikov A.L., Mikhalev A.V. (2012) Kol'tsa chastnykh graduirovannykh assotsiativnykh kolets. I. Fundamental'naya i prikladnaya matematika., V. 17, №2. - pp. 3-74.

3. Mushrub V.A. (1992) Endomorfizmy i radikaly kolets: Avtoref. dis. kand. fiz-mat. nauk. Moscow. - 11 p.

4. Mushrub V.A. (1992) Endomorfizmy i radikaly kolets: dis. kand. fiz-mat. nauk. Moscow. $158 \mathrm{p}$.

5. Mushrub V., Sukhorukova I. (2017) Some properties of the lattice of $f$-closed right ideals. To appear.

6. Sukhorukova I., Mushrub V. (2016) The Jacobson radical and ring endomorphisms. Ural'skiy nauchnyy vestnik, V. 4. - p. 155164.

7. Tuganbayev A.A. (2009) Teoriya kolets. Arifmeticheskiye kol'tsa i moduli. Moscow: MCCME. - 472 p. Available: http://e.lanbook.com/book/9425 (Accessed: 10.07.2017).

8. Matczuk J. (1988) Extended centroids of skew polynomial rings. Mathematical Journal of Okayama University, Vol. 30. - P. 13-20.
9. Montgomery S., Passman D.S. (1984) Outer Galois theory of prime rings. Rocky Mountain Journal of Mathematics. - Vol. 14, № 2. - P. 305-317.

10. Jordan, D. A. (1982) Bijective Extensions of Injective Ring Endomorphisms. Journal of the London Mathematical Society, s2-25: p. 435448. doi:10.1112/jlms/s2-25.3.435

11. Mushrub V.A. (1995) Kriteriy poluprostoty kol'tsa kosykh mnogochlenov. Fundamental'naya i prikladnaya matematika, V. 1. No 3. - p. 701 - 709. Available: http://mi.mathnet.ru/rus/fpm/v1/i3/p701 (Accessed: 10.07.2017).

12. Mushrub V.A. (1996) O nil'potentnosti podkolets kosykh gruppovykh kolets. Fundamental'naya i prikladnaya matematika, V. 2, No 4. - p. 1227. Available: http://mi.mathnet.ru/fpm194 (Accessed: 10.07.2017).

13. Mushrub V.A., Sukhorukova I.V., Belyayev A.A., Pavlovskiy V.V. (2016) Ob invariantnosti strogo nasledstvennykh radikalov otnositel'no endomorfizmov// Innovatsii i investitsii, № 4. - p. 150-154.

14. Matczuk J. S. (2007) Cohn-Jordan extensions . Communications in Algebra. V. 35, №3. - p. 725-746. https://arxiv.org/abs/1110.1446 Available: 10.07.2017) 